\title{
Efferent Pathway
}

National Cancer Institute

\section{Source}

National Cancer Institute. Efferent Pathway. NCI Thesaurus. Code C13081.

A sensory pathway that conducts impulses away from the central nervous system. 